\title{
TECNOLOGIA APLICADA À EDUCAÇÃO NOS CURSOS DE LICENCIATURAS
}

Orly Marion Webber ${ }^{1 *}$

\section{Resumo}

\begin{abstract}
Este trabalho apresenta uma proposta que possibilitará, aos Cursos de Licenciatura, a gestão competente não só do seu próprio desenvolvimento junto às transformações pelas quais passa a sociedade, como de propiciar à comunidade escolar condições de acesso a valores intelectuais comprometidos com as múltiplas e constantes transformações nos vários contextos aos quais estão inseridos e possibilidade de participação efetiva nesse processo, produzindo e socializando o conhecimento em benefício de toda a sociedade, mediante as variadas ferramentas tecnológicas.
\end{abstract}

Palavras-chave: Tecnologia Educacional - Licenciaturas - Formação de Professores.

\section{Abstract}

This work presents a proposition that will ease the teacher formation courses in its own development on the changes of the various contexts they are inserted and possibilities of effective participation in this process, producing and socializing knowledge in the bennefit of the whole society, through a variety of technological tools.

Keywords: Educational Techonology - Licentiatiships - Teacher Formation.

\section{As licenciaturas ea tecnologia}

O papel que o avanço tecnológico vem desempenhando para modificar as relações nesse início de século é visível. No âmbito educacional, é plenamente reconhecido que também vivenciamos uma crise e que esta afeta as Universidades, que não só respondem pela formação dos profissionais que vão atuar na sociedade como recebe dessa sociedade as conseqüências de uma escola básica deteriorada pela falta de política séria de qualificação e promoção profissional, levando ao desprestígio social que atinge a carreira de professor. Mais ainda, responde pelos profissionais que formarão outros profissionais, referindo-se mais precisamente aos professores dos cursos de Licenciatura.

\footnotetext{
* Mestranda em Educação - PUCPR
} 
A importância da tecnologia diante da complexibilidade da docência em todas as áreas do conhecimento é relevante frente ao processo de profissionalização e competitividade que se apresenta na sociedade contemporânea.

A atuação do professor que é, essencialmente, produtor e disseminador de conhecimentos, apresenta ainda algumas características diversas do que constitui o novo perfil da prática educacional ora pertinente.

As dúvidas, os anseios, os conflitos que perpassam a relação que 0 professor deve ter com sua própria competência constituem uma problemática que interfere com sério grau de importância no processo de aprendizagem, uma vez que nem todos os profissionais da educação estão aptos para a atual ausência de limites entre o estudo e o trabalho, para produzir o seu conhecimento e promover essa construção junto aos seus alunos buscando também a politecnia, preparado-os para interagir em diversos ramos das ciências, para o cultivo do novo, da criação, conforme exige também a constante e veloz transformação que tem ocorrido em todas as áreas do conhecimento e não só no mercado de trabalho.

As instituições estão sendo cada vez mais questionadas quanto a sua capacidade, importância e competência, fato que leva a mudanças que por sua vez exigem outras mudanças, quem levam às rápidas transformações que a sociedade percebe.

Ao se comentar o papel do professor ou das instituições educacionais não podemos acreditar que, em contato com uma tecnologia de vanguarda, um e outro estarão necessariamente copiando modelos predeterminados por empresas que desenvolvem essa tecnologia. Pelo contrário, o que pode ocorrer é que na medida em que a tecnologia auxiliar de fato a produção do conhecimento em instituições de ensino em seus mais variados graus, como já vem ocorrendo em alguns setores, as empresas e quaisquer outras instituições não educacionais é que buscarão na escola o aprendizado sobre a aplicabilidade da tecnologia na formação de novos profissionais, conforme DRUCKER, 1989:

Dentro de vinte anos, a típica organização de grande porte - seja ela uma grande empresa ou um grande órgão público - não terá mais do que a metade dos níveis administrativos de sua equivalente hoje, e não mais de um terço do número de "administradores". (...) É muito mais provável que ela se assemelhe a organizações que hoje nem os gerentes profissionais nem os estudantes de administração dão muita atenção: o hospital, a universidade, a orquestra sinfônica. Pois, da mesma forma como essas organizações, a empresa - e cada vez mais os órgãos governamentais - será também fundamentada no conhecimento, também formada basicamente de especialistas que dirigem e disciplinam o seu próprio desempenho mediante um feedback organizado de seus colegas e clientes. Será, em suma, uma organização fundamentada na informação. 
As cadeias organizacionais estão atentas a esse modelo que se instaura, e a visão e a participação do professor como agente exemplar na contínua transformação da sociedade torna-se cada vez mais decisiva, também quanto à interação tecnologia e educação.

A inserção de tecnologia aplicada à educação nos cursos de licenciatura certamente propiciará uma inter-relação entre o que é oferecido nesses cursos e o que será encontrado no cotidiano das instituições onde o estudante desenvolverá suas atividades profissionais. Não é mais admissível que os cursos de graduação não contemplem a utilização de recursos tecnológicos no aprimoramento da formação de futuros professores que poderão também, e por que não, contribuir para um encaminhamento mais adequado ao processo de desenvolvimento dessa tecnologia, hoje nas mãos de técnicos nem sempre comprometidos com a visão pedagógica de utilização desses recursos.

As transformações sociais interferem diretamente no comportamento profissional dos educadores que devem delinear caminhos para sensibilização de graduandos dos cursos de licenciatura quanto ao desenvolvimento de habilidades referentes à tecnologia aplicada à prática pedagógica. Também há de se analisar o papel da pesquisa científica na formação e capacitação continuada de docentes utilizando a tecnologia a serviço da educação.

Um programa de inserção e utilização da tecnologia de ponta disponível à área educacional, desde a informática e internet até a elaboração de projetos e cursos à distância, passando pela capacidade de avaliação de um software educacional, torna-se imprescindível, pois a tecnologia e a informação estão à disposição de quem desejar fazer uso de seus recursos como meios facilitadores de qualquer tipo de trabalho, economizando tempo e diminuindo distâncias. Os benefícios dependerão também do encaminhamento do processo e da criatividade e competência de cada docente pesquisador.

\section{Oprofessorea tecnologia}

Novos caminhos estão sendo traçados e, apesar de todos os desvios e barreiras que o avanço da educação enfrenta, devemos crer que eles serão superados um a um e mesmo que de forma lenta e penosa, os nossos alunos, amparados pela liberdade de pensamento e de expressão e com a esperada democratização do saber que a informática possibilita, serão capazes de ultrapassar os anos acadêmicos de forma vitoriosa, sem perder a consciência de que nunca poderão deixar de lado o aprimoramento profissional e social por meio da pesquisa.

No desenrolar da história, o professor traz saberes plurais, cuja profissão foi traduzida primeiro pela Igreja como uma vocação missionária e em seguida transformou-se em função controlada pelo Estado, conforme NóvoA 
(1992, p. 15). O que então confere identidade profissional ao profissional professor que não seja a de um eterno transmissor de saberes já consolidados? Onde está o pesquisador e promotor da fertilização e construção do conhecimento nas instituições de ensino?

A ciência pode ser construída a partir do senso comum, da maneira de como se interfere na realidade e a recompõe. Esse fato também ocorre na perspectiva dos educandos, conforme CASTELL, 1996:

Os educadores precisam entender que as diferentes identidades entre os jovens estão sendo produzidas em esferas geralmente ignoradas pelas escolas. Aqui caberia incluir-se uma análise de como a pedagogia trabalha para produzir, circular e confirmar formas particulares de conhecimento e de desejos naquelas esferas públicas e particulares em que sons, imagens, textos e cultura eletrônica tentam utilizar o significado a favor e contra a possibilidade de estender a justiça social e a dignidade humana.

A formação do profissional professor, que não tem uma identidade única, apresenta uma história de formação que nos dias de hoje se traduz por competência no enquadramento de curńculos na sua prática diária. Essa formação tem que se modificar. O professor ainda não é visto e não se vê como um artífice de uma sociedade, mas como um reprodutor de saberes preestabelecidos como verdades.

Deve-se, antes de tudo, conhecer o perfil do professor que se apresenta hoje diante da Universidade, bem como, nesta, a melhor forma de atuarjunto aos educandos. Já foram apresentados a esses professores, mediante de vasta bibliografia, subsídios pertinentes para repensar sua prática junto à sociedade, junto ao jovem, refletir seus resultados, redefinir seus reais objetivos, mas é na perspectiva de contribuir cientificamente com a análise do quanto esse avanço está efetivamente se dando de forma dinâmica e apontar para uma constante redefinição da práxis para obtenção de melhores condições que se subsidia a apresentação e apropriação de novas tecnologias aplicadas à prática pedagógica.

Sendo assim, o processo de democratização dos saberes tecnológicos aplicados à educação por meio dos cursos de licenciatura das instituições de ensino superior deverá ter por critérios a constatação de que os seus conteúdos vêm ao encontro das requisições filosóficas e teónicas nas quais o projeto político-pedagógico da instituição está embasado sem deixar de buscar compreender os anseios dos futuros profissionais e também de outros setores da sociedade, senão todos.

Por outro lado, há requisições dos meios de sustentação do sistema econômico e social que estão a exigir cada vez mais criatividade, flexibilidade e conhecimentos da microeletrônica, habilidades indispensáveis a todos os cidadãos que desenvolvem qualquer atividade, independente de seu lugar nas esferas econômica ou política-ideológica. 
O profissional da educação não pode, portanto, ter medo da diversidade e estar ciente de que o desenvolvimento científico e tecnológico mundial interfere diretamente nos paradigmas educacionais, ou seja, no seu "conjunto de ilustrações recorrentes e quase padronizadas de diferentes teorias nas suas aplicações conceituais, instrumentais e na observação" (KUHN, 1998, p. 68), produzindo alterações na educação com a efetivação de metodologias que se apropriam do uso de tecnologia, propiciando como consequêencia a melhoria da aprendizagem num contexto informatizado. Um quadro adequado com a realidade contemporânea aponta para um perfil que caracteriza a competência do profissional da educação, como a capacidade de propôr e aliar-se a projetos relevantes julgados a partir de seu espírito de pesquisador aberto para aprender e interagir de acordo com suas análises pessoais.

As principais correntes do pensamento cientíico, os instrumentos e fontes de pesquisa e a utilização de serviços de rede local e internet, auxiliarão o profissional da educação a desenvolver sua criatividade, versatilidade, tomando-o, conseqüentemente, capaz de apropriar-se dos recursos tecnológicos disponíveis que o auxiliarão na prática e disseminação da pesquisa científica enquanto metodologia da ação pedagógica. A prática e disseminação da pesquisa científica enquanto metodologia da ação pedagógica também poderá ser incentivada pois "o homem limitado e restrito do início do século XX é gloriosamente substituído, pela ciência do nascer do século XXI, por um novo homem, múltiplo, holístico, ilimitado na capacidade de expansão de seu cérebro." (ANTUNES, 1998, p.134).

A evolução tecnológica impulsiona a inserção de novas ferramentas e conceitos no processo ensino-aprendizagem, auxiliando não na instrução, e sim, na formação do cidadão do futuro, rastreando suas vocações e dando-lhe oportunidade de agregar valor intelectual e profissional.

Qualquer processo formativo só tem a ganhar se se preocupar, antes de mais nada, com a construção da capacidade de construir; como regra, qualquer curso deveria começar com um "ciclo básico" comum propedêutico, no qual, todos, sem exceção, seriam motivados a passar do aprender para o aprender a aprender; essa iniciativa vale particularmente para os cursos de graduação. (...). A sociedade moderna, todavia, exige um cidadão capaz de estar à frente, comandando o processo exponencial de inovação, não correndo a trás, como se fora sucata. Enfrentar desafios novos, avaliar os contextos sóciohistóricos, filtrar informação, manter-se permanentemente em processo de formação são responsabilidades inalienáveis para quem procura ser sujeito de sua própria história. (DEMO, 1996, p.32)

Seguindo a análise de DEMo, torna-se indispensável refletir sobre o papel do educador frente aos novos rumos da educação, apresentar as contribuições que as novas tecnologias podem acrescentar na prática educativa, 
subsidiar o docente no aprofundamento teórico-prático para a utilização dos recursos tecnológicos, desde os mais simples até os mais complexos, incentivar a proposta de projetos pedagógicos que disseminem a pesquisa científica e propiciem a abertura para novas idéias em benefício do processo educacional.

\section{Atecnologia chega à escola}

No que diz respeito à tecnologia educacional, o processo de informatização das escolas públicas e privadas do país encontra-se em andamento, e o educador deve buscar a interação tecnologia/educação com vistas ao seu papel insubstituível de produtor e incentivador da construção do conhecimento, conforme REINATO $(1997,05)$ :

Estamos diante de uma bela demonstração de que a modernização da educação é séria demais para ser tratada somente por técnicos. É um caminho interdisciplinar, e a aliança da tecnologia com o humanismo é indispensável para criar uma real transformação. Ao meu ver, o caminho não é novo, mas são novos os meios para percorrê-los. Em síntese, só terá sentido a incorporação de tecnologia na educação como na escola, se forem mantidos os princípios universais que regem a busca do processo de humanização, característico caminho feito pelo homem até então.

Junto a esses objetivos, apresenta-se como perfil do profissional da educação, a capacidade de avaliar concepções pedagógicas buscando interação das diversas áreas do conhecimento, por meio da multidisciplinaridade e 0 domínio de conhecimentos necessários para integrar uma sociedade que se coloque à frente das mudanças que o desenvolvimento científico-tecnológico apresenta.

Tomemos como exemplo o estado do Paraná em que a grande parte das escolas da rede pública (e provavelmente da rede privada) de ensino médio já contam com laboratórios de informática destinados ao uso pedagógico, graças a programas públicos de aquisição de computadores (o Programa Nacional de Informática na Educação, por exemplo). Seja com uma sala com três micros até quatro laboratórios com vinte máquinas cada um, como possui o Colégio Estadual do Paraná, o processo de utilização desses equipamentos já iniciou nas escolas, mas o seu desenvolvimento é lento principalmente em instituições que não possuem programas de capacitação destinados aos professores, principais agentes responsáveis pela utilização pedagógica desses meios. Essa é a causa pela qual as instituições de ensino médio e de formação de professores não têm avançado na formulação de novas metodologias que 
visem não ao uso pelo uso, mas a adequação desses recursos como mais um auxiliar na promoção da aprendizagem.

Muitos cursos de licenciatura das instituições de ensino superior ainda não contemplam em seus curnículos essa adequação. E deve-se deixar claro que não se trata de uma adequação passiva em que apenas conhecimentos técnicos e de operacionalização serão repassados para que sejam reproduzidos. Ao entrar em contato com uma tecnologia mais avançada, o professor fatalmente encontrará aplicabilidades pertinentes para esses recursos na sua área de atuação, seja levando o seu trabalho, elaborado com a ajuda da máquina, até seus alunos, seja junto com seus alunos criando e produzindo. $\mathrm{O}$ computador e outros recursos tecnológicos não vêm, de forma alguma, substituir outros meios disponíveis para a prática do magistério. Excluindo-se a antiga máquina de datilografia, todos as outras ferramentas continuam fazendo parte do universo educacional, seja utilizada por alunos ou professores. Cysneiros (1999, p. 32) sugere:

O ideal será que o educador aprenda a lidar com as TI durante sua formação regular, nos cursos de licenciatura e de pedagogia, em disciplinas mais ou menos com os nomes de "Tecnologia Educacional" ou "Tecnologias da Informação na Educação" e de modo mais detalhado nas didáticas de conteúdos específicos (Metodologias de Ensino). Algumas faculdades já oferecem tais disciplinas, porém ainda demorará alguns anos para que haja mudanças neste sentido, pois a Universidade não assimila facilmente novidades.

O que ocorre é que as transformações na área tecnológica são tão rápidas que ainda encontramos mestres com dificuldades para utilizar um videocassete ou o próprio retroprojetor, quanto mais sensibilizados para preparar uma aula em que um software de apresentação ou de simulação faça parte dos seus recursos disponíveis.

Vale lembrar aqui duas questões muito importantes que afetam a plena utilização de recursos informatizados na prática pedagógica que são a disponibilidade de técnicos em informática que acompanhem o processo, dando apoio ao professor e o problema do tempo disponível para o preparo do material a ser utilizado. Quanto à questão dos técnicos, o importante é que profissionais da área de informática também estejam dispostos a colaborar com o processo educacional, como mais um campo de trabalho, estando também abertos a mudanças e inovações, sendo criativos, conhecedores do projeto pedagógico da escola e participantes de todo o processo de utilização de recursos informatizados na prática docente.

Quanto ao problema do tempo, é indiscutível, por exemplo, que o tempo despendido na elaboração de uma apresentação com gráficos, textos, 
som e imagem, seja recuperado na freqüência com que um material já pronto possa ser reutilizado com significativa facilidade de adaptações que se façam necessárias. $\mathrm{O}$ armazenamento desses trabalhos e a rapidez com que serão encontrados para nova utilização compensam o tempo gasto na sua confecção. Segundo MORAES (1997, p. 15):

Uma nova ecologia cognitiva proporcionada por ambientes adequadamente informatizados, onde o professor não é a única fonte de informação, pressupõe um ambiente enriquecido de códigos simbólicos, de representações por imagens, sons e movimentos, disponíveis para que os alunos possam interagir com eles, formular e testar hipóteses, estabelecer relações, produzir simulações rápidas e fáceis, construir conhecimentos que tenham correspondências com a sua forma de pensar e compreender os fenômenos e os fatos da vida. Nesses ambientes poderemos partir de problemas, atividades e projetos contextualizados e individuais, vivenciar interações sociais mais ricas e que também se constituem em novas fontes de informações.

Alunos poderão usar seus trabalhos universitários na profissão que escolheram, professores e alunos terão acesso a infinitas pela internet, e a troca de idéias e materiais será agilizada por e-mails e disquetes com custos reduzidos. Poucos divulgam seus livros pela rede, mas isso já ocorre com freqüência quando se trata de um artigo, por exemplo. Essa é a facilidade que poderá levar à tão promulgada democratização dos saberes, desde que não só uma elite é que possa ter acesso à tecnologia voltada para a educação.

Utilizando um software de apresentação, o professor ou aluno deverá ter capacidade de análise e síntese mais apuradas, pois ele não permite muito texto e aceita a inclusão de fotos, filmes, som, o que obriga o usuário a cercar-se de tópicos e imagens que apenas direcionarão seu discurso. O erro de se ler uma transparência para os ouvintes e ficar por isso mesmo é evitado já na elaboração do material. Conta-se também com a melhoria na apresentação de trabalhos digitados dado o grande número de recursos que um editor de texto oferece. Não há mais como errar na ortografia, na formatação, na configuração estética de um texto qualquer. Se ainda temos textos mal escritos, trata-se de lacunas deixadas pelo processo educacional pelo qual passam os graduandos, principalmente em relação ao uso da língua escrita. Isso fica claro quando observamos textos de conversas online.

MORAES (1997, p. 04) afirma:

Informações e conhecimentos são matérias-primas inexauriveis, podendo ser usadas como fontes geradoras de novos conhecimentos e novas compreensões. Dados, informações, símbolos, imagens, cultura e valores são considerados recursos fundamentais da economia atual. Hoje, o valor principal já não está na combinação da terra, capital e trabalho, mas sim no 
nível de conhecimento que uma população dispõe e sua capacidade de transmitir e reconstruir conhecimento, o que traduz sua competência no manuseio do instrumental tecnológico moderno.

A implantação de computadores nas instituições de ensino, especialmente aquelas voltadas para a formação de professores, é importante na medida em que determina o uso da tecnologia da informática para o desenvolvimento de atividades educativas individuais ou coletivas. A informática voltada para a educação tem como objetivo ampliar as possibilidades de acesso e manipulação das informações, como também de desenvolvimento e aprimoramento dos processos cognitivos por meio de softwares e hardwares.

Percebe-se, porém, que o uso dessas ferramentas está ocorrendo de uma forma descontextualizada do currículo, às vezes com uma supervalorização dos recursos informatizados, que desaparecem com outras atividades educativas ou com o seu uso reproduzindo o velho, além de contar com o envolvimento de uma pequena parcela dos professores, seja por despreparo ou desinteresse.

Também há casos em que o professor está sendo obrigado a trabalhar com informática ou então proibido de freqüentar o laboratório de informática da escola. Muitas vezes ele vê seu trabalho ser desqualificado e passa a ser um mero "executor" de "pacotes" de softwares. Com certeza, deve haver mais investimentos na formação dos professores que precisam entender muito mais de novas tecnologias educacionais.

É necessário, por exemplo, que os professores participem da seleção dos softwares e possam familiarizar-se com os programas disponíveis no mercado, tenham contato com a tecnologia voltada para o seu cotidiano e repensem a sua prática pedagógica, aliando sua experiência à ferramenta computador. Também deve haver sensibilidade para perceber qual é o momento em que ele deve utilizar os recursos da informática, como e por que utilizá-los.

\section{Conclusões}

Na prática pedagógica na Universidade, especialmente na graduação, é que está a base de toda uma classe de trabalhadores que representa um dos blocos mais importantes nas relações sociais, visto que estão ligados a todas as áreas do conhecimento. Segundo CunHa (1996, p. 43) "o que é ensinado nas universidades depende das relações entre produção e educação ditadas pelo Estado e é, ao mesmo tempo, produto da autonomia da educação." Portanto, a utilização dos recursos tecnológicos voltados para a educação deve estar aliada ao projeto pedagógico da instituição como uma metodologia interdisciplinar presente principalmente nos currículos das licenciaturas, visto 
que são cursos que formam professores que trabalharão em escolas que já foram contempladas com esses recursos.

A utilização da tecnologia voltada para a educação caracteriza-se pelo seu aspecto multidisciplinar, uma vez que o seu desenvolvimento envolve todas as áreas do conhecimento, mas o licenciado não pode se tornar um gorila amestrado, isto é, alguém que usa a tecnologia sem fazer uma reflexão crítica sobre sua aplicabilidade. É importante não deixar que a utilização da tecnologia ameace um espaço que normalmente é deixado aos conteúdos; é fundamental, também, evitar a idéia muito comum que é a de pensar que ela se constitui em uma solução milagrosa para todos os problemas da educação.

Necessita-se, portanto, em inúmeras instituições de ensino, de uma proposta que possibilite ao graduando dos cursos de licenciatura a gestão competente não só do seu próprio desenvolvimento pessoal e profissional, como de propiciar à comunidade escolar condições de acesso a valores intelectuais comprometidos com as múltiplas e constantes transformações nos vários contextos aos quais estão inseridos e possibilidade de participação efetiva nesse processo, produzindo e socializando o conhecimento em benefício de toda a sociedade, mediante as variadas ferramentas tecnológicas.

\section{Referências Bibliográficas}

ANTUNES, Celso. As inteligências múltiplas e seus estímulos. Campinas: Papirus, 1998.

BRASIL,Ministério da Eucação e do Desporto. Secretaria de Educação à Distância. Programa Nacional de Informática na Educação. Brasília, 1997.

CASTELLS, Manuel. Novas perspectivas críticas para a educação. Porto Alegre: Artes Médicas, 1996.

CUNHA, M. I.; LEITE, D. B. C. Decisões pedagógicas e estrutura de poder na universidade. Campinas: Papirus, 1996.

CYSNEIROS, P. G. Novas Tecnologias na Sala de Aula: Melhoria do Ensino ou Inovação Conservadora? IX ENDIPE - Encontro Nacional de Didática e Prática da Ensino. Águas de Lindóia, São Paulo, 4 a 8 de maio de 1998. Anais II, vol. 1/1, pp. 199-216.

DEMO, Pedro. Educação e qualidade. 3. ed. Campinas: Papirus, 1996.

MORAES, M.C.B. O paradigma educacional emergente. Tese de doutorado apresentada à Pontifícia Universidade Católica de São Paulo, PUC/SP: São Paulo, 1996. 
MORAES, M. C. Subsídios para fundamentação do programa nacional de informática na educação. SEED/MEC, jan. 1997.

REINATO, Eduardo José. Informática e educação. <<http// www.educasoft.com.br >>.

VALENTE, José Armando. Computadores e conhecimento: repensando a educação. Campinas: Gráfica Central da UNICAMP, 1993.

VASCONCELOS, Celso S. Construção do conhecimento em sala de aula. Cadernos Pedagógicos do Libertad - 2. São Paulo: 1991.

Recebido em: 02/03/02

Aprovado em: 20/05/02 